\title{
Research on the Reason for Transformer Differential Protection Mal-operation Caused by Sympathetic Inrush
}

\author{
Xiangfei Sun, Hongchun Shu, Jianping Zhou \\ Department of Electrical Power Engineering, Kunming University of Science and Technology, Kunming, China \\ Email: fly_beauty@163.com,kmshc@sina.com, fqyd926@163.com
}

Received March, 2013

\begin{abstract}
The paper is concerned with whether CT transient saturation, which caused by sympathetic inrush, is the direct reason for mal-operation of transformer differential relays. In order to analyze transforming characteristics of saturated CT, the gain of each harmonic current transforming from primary winding to secondary winding of transient saturation CT is calculated. Based on the fact that series sympathetic inrush is easier to lead differential relay mal-operation than parallel sympathetic inrush, the effect of CT saturation on differential relay in the case of both parallel sympathetic inrush and series sympathetic inrush are investigated respectively. Theory analysis and simulation show that higher harmonic will be transferred by saturated CT more easily than lower harmonic, and then the second harmonic proportion of CT secondary side is higher than that of CT primary side. Thus CT transient saturation itself is not essential reason for differential relay mal-operation. Parallel sympathetic inrush and series sympathetic inrush will lead to different location CT saturated. Parallel sympathetic inrush will lead to CT located system side saturated; second harmonic ratio of differential current increase and dead angle is large. Series sympathetic inrush will lead to CT located load side saturated; second harmonic ratio of differential current decrease and dead angle is small.
\end{abstract}

Keywords: Sympathetic Inrush; CT Transient Saturation; Transformer; Differential Protection

\section{Introduction}

When a transformer is energized in either series or parallel with other transformers that are already in service, it will result in a sympathetic interaction between the incoming transformer and those that are in operation [1-4]. In the recent years, it has reported that the transformer differential relay mal-operated due to sympathetic inrush [5-10]. It is worth emphasizing that most of reported events were cause by series sympathetic inrush [6-10].

The physical mechanism and waveform characteristics of sympathetic inrush have been analyzed in many literatures [11-16]. In brief, the reason for generation of both magnetizing inrush and sympathetic inrush is iron core saturation. Moreover, the previous researches show that the waveform of sympathetic inrush is similar to magnetizing inrush in a cycle. But the decay of sympathetic inrush is more slowly and sympathetic inrush will lead to CT saturation more easily.

Therefore, CT transient saturation caused by DC component of sympathetic inrush is the accepted reason for transformer differential protection mal-operation. How- ever, only simple simulations and analysis were given to analyze the effect of CT saturation on transforming sympathetic inrush, and necessary theoretical calculating is not carried out. Moreover, much research assumes that two transformers are in parallel and the operated one is unload. In practice, the operation transformer is always loaded and series sympathetic inrush is easier to lead differential relay mal-operation.

Aim to discover the real reason for mal-operation of transformer differential relay caused by sympathetic inrush, the formula for calculating each harmonic transforming from primary winding to secondary winding of transient saturation CT is derived firstly. Then theoretical analysis and simulation are carried out to discover the internal reason for series sympathetic in rush is easier to lead differential relay mal-operation than parallel sympathetic inrush in detail.

\section{Transforming Characteristics of Saturated CT}

Because of slowly decaying DC component in sympathetic inrush, the curves of sympathetic inrush deviate from time axes. As we known, CT can hardly transfer decaying DC component, and decaying DC component may cause core of CT in saturation. The equivalent circuit of CT is shown in Figure 1. $L_{1}$ and $R_{1}$ mean the equivalent inductance and resistance of CT primary side respectively; $L_{2}$ and $R_{2}$ mean the equivalent inductance and resistance of CT secondary side respectively; $L_{L}$ and 
$R_{L}$ mean the equivalent inductance and resistance of CT load respectively; $L_{\mathrm{m}}$ means magnetizing inductance of $\mathrm{CT} ; i_{1} 、 i_{2} 、 i_{m}$ mean primary side, secondary side and magnetizing current of CT.

The CT primary side current $i_{1}$ is the current of power system, and is independent of CT. So, the current $i_{1}$ can be looked as a current source. As a result, $L_{1}$ and $R_{1}$ is independent of CT saturation. $L_{2}, R_{2}, L_{\mathrm{L}}$ and $R_{\mathrm{L}}$ is series and can be replaced by $L_{L}^{\prime}$ and $R_{L}^{\prime}$. Where $L_{L}^{\prime}=L_{2}+$ $L_{\mathrm{L}}, \quad R_{L}^{\prime}=R_{2}+R_{\mathrm{L}}$. Then circuit shown in Figure 1(a) can be converted to that shown in Figure 1(b). While slowly decaying DC component in sympathetic inrush, the decaying DC current will flow through magnetizing branch of CT mainly after a certain time. Thus CT is in transient saturation.

Supposing that, the fundamental and second hạrmonic component of CT primary side current $i_{1}$ are $I_{1,1}$ and $I_{1,2}$, and CT is saturated transiently with sympathetic inrush current. Then, the magnetizing inductance of CT will decrease from $L_{m}$ to $L_{m s}$. The each harmonic component $I_{2, n}$ of C.T secondary side current and the magnetizing current $I_{m, n}$ of CT will be

$$
\begin{gathered}
\dot{I}_{2, n}=\frac{j n w_{0} L_{m s}}{j n w_{0}\left(L_{m s}+L_{L}^{\prime}\right)+R_{L}^{\prime}} \dot{I}_{1, n} \\
\dot{I}_{m, n}=\frac{j n w_{0} L_{L}^{\prime}+R_{L}^{\prime}}{j n w_{0}\left(L_{m s}+L_{L}^{\prime}\right)+R_{L}^{\prime}} \dot{I}_{1, n}
\end{gathered}
$$

In equation (1) and equation (2), $n=1,2 \ldots N$, means each harmonic, $w_{0}$ means angular frequency. Therefore, the gains of each harmonic $K_{C T}(n)$ will be

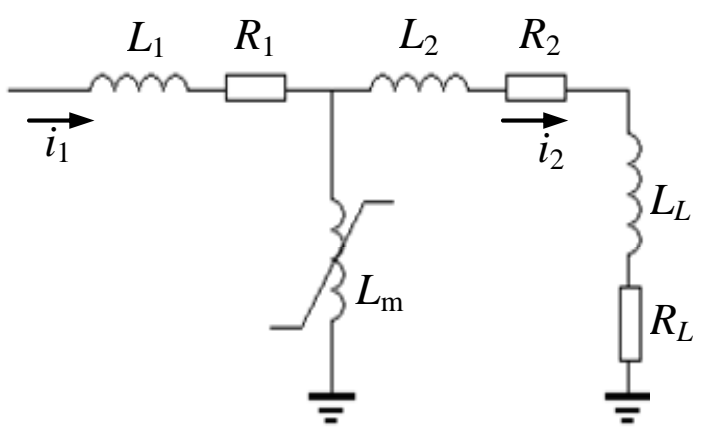

(a) Equivalent circuit of CT

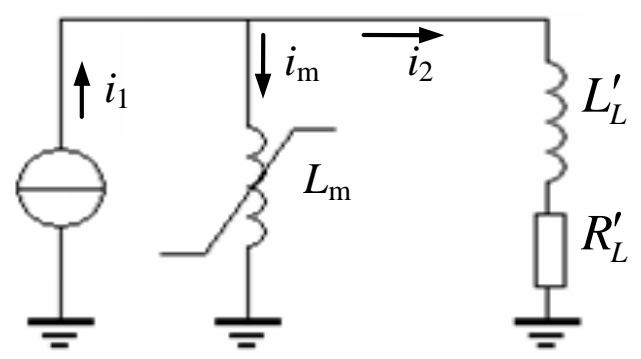

(b) Equivalent circuit for calculating

Figure 1. Equivalent circuits of current transformer.

$$
\begin{aligned}
K_{C T}(n) & =\left|\dot{I_{2, n}} / \dot{I_{1, n}}\right|=\left|\frac{j n w_{0} L_{m s}}{\mathrm{j} n w_{0}\left(L_{m s}+L_{L}^{\prime}\right)+R_{L}^{\prime}}\right| \\
& =\frac{n w_{0} L_{m s}}{\sqrt{\left[n w_{0}\left(L_{m s}+L_{L}^{\prime}\right)\right]^{2}+R_{L}^{\prime 2}}}
\end{aligned}
$$

The derivation of $K_{C I}(n)$ is

$$
\frac{\mathrm{d} K_{C T}(n)}{\mathrm{d} n}=\frac{w_{0} L_{m s} R_{L}^{\prime 2}}{\sqrt{\left[n w_{0}\left(L_{m s}+L_{L}^{\prime}\right)\right]^{2}+{R_{L}^{\prime 2}}^{3}}}
$$

From equation (4), $\frac{\mathrm{d} K_{C T}(n)}{\mathrm{d} n}>0$ can be got. It is can be seen that higher harmonic will be transferred by saturated CT more easily than lower harmonic. This implies that the second harmonic proportion of CT secondary side is higher than that of CT primary side.

\section{Effect of Parallel Sympathetic Inrush on Transformer Differential Relay with CT Saturation}

The electrical configuration used to analyze the sympathetic inrush that occurs between transformers in parallel is shown in Figure 2. Assuming that sympathetic inrush occurs in the transformer $T_{2}$ when the transformer $T_{6}$ is ennergized by closing beaker $K_{1}$.In Figure $2, I_{1}, I_{2}$, $I_{L}$ mean fundamental components of primary side, secondary side current of transformer $\mathrm{T}_{2}$ and load current respectively. Obviously, the sympathetic inrush mainly flows through $\mathrm{CT}_{1}$, and will lead to $\mathrm{CT}_{1}$ transient saturation more easily.

Firstly, supposing $T_{2}$ is no-load operating, i.e. $\dot{I}_{L}=0$, thus the current $I_{1}$ in $\mathrm{CT}_{1}$ is sympathetic inrush. According to section 2, second harmonic ratio of sympathetic inrush will be amplified by saturated CT, which is help to second harmonic restraint method. Even if sympathetic inrush lead to $\mathrm{CT}_{1}$ saturated, the transformer differential protection of transformer $\mathrm{T}_{2}$ will not mal-operate.

Next, the influence of sympathetic inrush on differential protection with loaded transformer $T_{2}$ will be analyzed as follow.

If $\mathrm{CT}_{1}$ is not saturated, the differential current $\dot{I}_{c d}$ of $\mathrm{T}_{2}$ can be expressed as

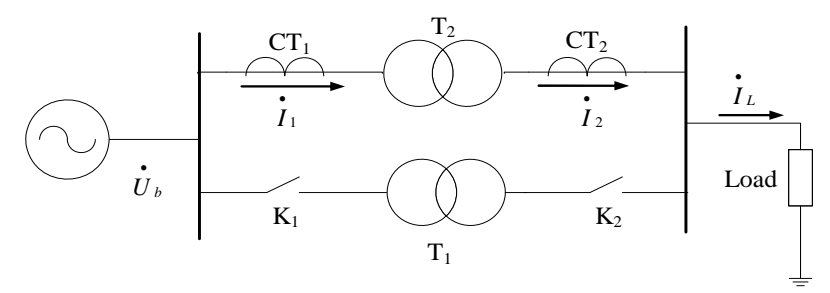

Figure 2. Electrical configuration of sympathetic inrush between transformers in parallel. 


$$
\dot{I}_{c d}=\dot{I}_{1}-\dot{I}_{2}
$$

If $\mathrm{CT}_{1}$ is saturated, the current $\dot{I}_{1}$ transfer from primary side to secondary side of $\mathrm{CT}_{1}$ wound be distorted to $I^{\prime}{ }_{1}$. As a result, differential current $I^{\prime}{ }_{c d}$ will be

$$
\dot{I}^{\prime}{ }_{c d}=\dot{I}^{\prime}{ }_{1}-\dot{I}_{2}=\dot{I}_{c d}-\left(\dot{I}_{1}-\dot{I}^{\prime}{ }_{1}\right)=\dot{I}_{c d}-\Delta \dot{I}
$$

where $\Delta \dot{I}=\dot{I}_{1}-\dot{I}^{\prime}{ }_{1}$ is the fundamental component of magnetizing inrush of $\mathrm{CT}_{1}$. Due to $\dot{I}_{c d}$ decreased by $\Delta I$, the fundamental component of differential current $I^{\prime}$ cd reduced accordingly. Moreover, second harmonic will be transferred by saturated $\mathrm{CT}_{1}$ more easily than fundamental component according to section 2. Therefọre, second harmonic proportion of differential current $I^{\prime}{ }_{c d}$ increases, which is help for second harmonic restraint method. In a word, the transformer differential protection of transformer $\mathrm{T}_{2}$ will not mal-operate when $\mathrm{T}_{2}$ operates with load and $\mathrm{CT}_{1}$ is saturated.

According to analysis above, parallel sympathetic inrush has a few effect on differential relay whatever the transformer operating with load or not.

\section{Effect of Series Sympathetic Inrush on Transformer Differential Relay with CT Saturation}

It is worth emphasizing that most reported events about transformer differential protection mal-operation caused by sympathetic inrush happened in power plants. The system electrical configuration is shown in Figure 3. Generator $G_{2}$ is in normal operation and supplies to the system by breaker $K_{3}$. Generator $G_{1}$ is cut off from the system, when no-load transformer $\mathrm{T}_{1}$ carry out energizing test by closing breaker $\mathrm{K}_{1}$, differential protection of transformer $\mathrm{T}_{2}$ may mal-operate.

The corresponding equivalent circuits of Figure $\mathbf{3}$ are shown in Figure 4. Assuming that $T_{1}$ is connected to system with no-load by closing breaker $\mathrm{K}_{1}$, and magnetizing inrush is generated, which lead to the sympathetic inrush in $T_{2}$. In fact, this sympathetic inrush is series sympathetic inrush.

In Figure 3 and Figure 4, $i_{1} 、 i_{m 1} 、 i_{L}$ mean the primary winding current of $\mathrm{CT}_{1}$, magnetizing inrush of $\mathrm{T}_{1}$ and load current respectively, that is

$$
i_{1}=i_{m 1}+i_{L}
$$

$i_{2} 、 i_{m 2}$ mean the primary winding current of $\mathrm{CT}_{2}$ and sympathetic inrush of $\mathrm{T}_{2}$ respectively, that is

$$
i_{2}=i_{m 2}+i_{1}=i_{m 2}+i_{m 1}+i_{L}
$$

Because the magnetizing inrush and sympathetic inrush have the opposite polarity, the primary winding current $i_{2}$ is almost symmetrical. Thus, the DC component of $i_{2}$ is small. On the contrary, the DC component of $i_{1}$ is great. Therefore, $\mathrm{CT}_{1}$ is easily saturated as well as $\mathrm{CT}_{2}$ is not saturated. The influence on differential protection with $\mathrm{CT}_{1}$ saturation will be analyzed in detail as follow.

In Figure 4, $L_{S}$ and $R_{S}$ are inductance and resistance of generator $\mathrm{G}_{2}$ respectively. $R_{21}$ and $L_{21}$ are leakage impedances of $\mathrm{T}_{2}$ primary winding; $R_{22}$ and $L_{22}$ are leakage impedances of $\mathrm{T}_{2}$ secondary winding. $R_{11}$ and $L_{11}, R_{12}$ and $L_{12}$ are leakage impedances of $T_{1}$ primary and secondary winding respectively. $L_{1 \mathrm{~m}}$ and $L_{2 \mathrm{~m}}$ are exciting inductances of $\mathrm{T}_{1}$ and $\mathrm{T}_{2}$ respectively.

If $\mathrm{CT}_{1}$ and $\mathrm{CT}_{2}$ are not saturated, the differential current $i_{c d}$ of $T_{2}$ can be expressed as

$$
i_{c d}=i_{1}-i_{2}
$$

If $\mathrm{CT}_{1}$ is saturated, the current $i_{1}$ transfer from primary side to secondary side of $\mathrm{CT}_{1}$ wound be distorted to $i_{1}$. Equation (8) and Equation (9) show that $i_{c d}=-i_{m 2}$. As a result, differential current $i_{c d}$ will be

$$
i_{c d}^{\prime}=i_{1}^{\prime}-i_{2}=i_{c d}-\left(i_{1}-i_{1}^{\prime}\right)=i_{c d}-\Delta i=-i_{m 2}-\Delta i
$$

where, which is the magnetizing in rush of $\mathrm{CT}_{1}$. Due to the load current $i_{L}$ has opposite phase with- $i_{m 2}$, the magnetizing inrush of $\mathrm{CT}_{1}$ makes the fundamental component of differential current $i_{c d}$ increased.

Second harmonic components of $i_{c d}, i_{m 2}, i_{m 1}$ and are represented by $i_{\mathrm{sc} 2}^{r}, i_{\mathrm{m} .2}, i_{\mathrm{m} .2}$ and respectively. Then, Equation (10) can be rewritten as

$$
\dot{I}_{c d, 2}^{\prime}=-\dot{I}_{m 2,2}-\Delta \dot{I}_{2}
$$

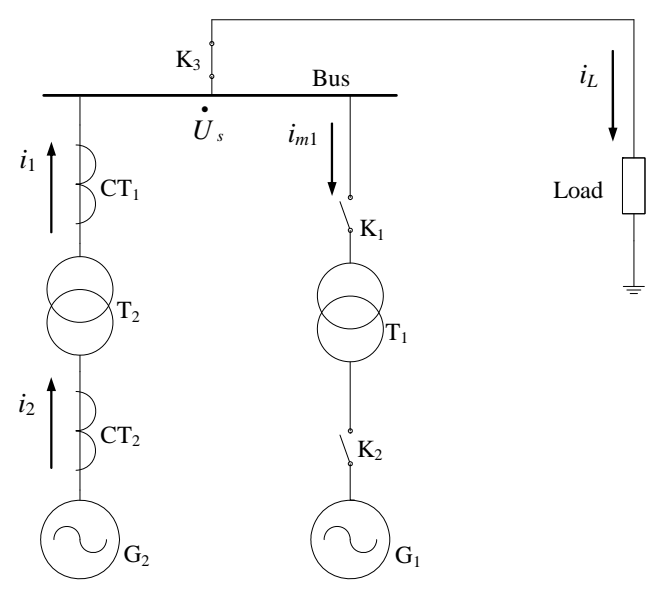

Figure 3. Electrical configuration of sympathetic in rush between transformers in series.

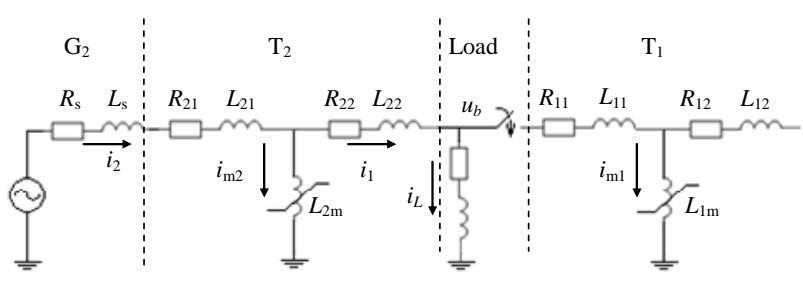

Figure 4. Equivalent circuits of sympathetic in rush between transformers in series. 
According to Equation (11), the corresponding pastors' graph is shown in Figure 5. As indicated in Figure

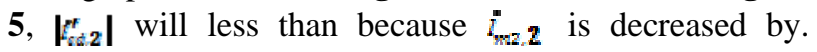
That means $\mathrm{CT}_{1}$ saturation will make the second harmonic component of differential current decreased.

In conclusion, $\mathrm{CT}_{1}$ saturation leads to the fundamental component of differential current increased whereas the second harmonic component of differential current decreased. As a result, the second harmonicratio of differential current will decrease. If second harmonic ratio is less than threshold, the second harmonic restraint method will become invalid. So bad influence will be caused to differential protection, the series sympathetic inrush is easy to lead differential relay mal-operation.

\section{Simulation Result and Analysis}

According to the simulation model shown as Figure 2, simulation results are shown in Figure 6. For clearly, Figure 6 shows the partial waveforms only. Figure 6(a), (b), (c) show that parallel sympathetic inrush lead to $\mathrm{CT}_{1}$ saturated, that is slowly decaying DC component in sympathetic inrush cause core of $\mathrm{CT}_{1}$ saturated, thus magnetizing inrush generates in $\mathrm{CT}_{1}$. As expected, Figure 6(d) shows second harmonic ratio of differential current of transformer $\mathrm{T}_{2}$ increaseafter $\mathrm{CT}_{1}$ saturate. Furthermore, Figure 6(e) indicates that dead angle of differential current is large enough. Therefore, parallel sympathetic inrush is not easy to cause differential protection mal-operation either adopting second harmonic restraint method or adopting dead angle restraint method.

According to the simulation model shown as Figure 3, simulation results are shown in Figure 7. Since switching $K_{1}$ to energize transformer $T_{1}$ lead to series sympathetic in rush generate in the already connected transformer $T_{2}$. As analyzed in section 4 , the series sympathetic in rush cause $\mathrm{CT}_{1}$ saturated. Figure 7(a) shows that $\mathrm{CT}_{1}$ saturation lead to second harmonic ratio of differential current of transformer $\mathrm{T}_{2}$ decreased. While second harmonic ratio is less than $15 \%$, the second harmonic restraint method is invalid. As the result, the differential protection will mal-operate, the corresponding motion curves is shown in Figure 7(b). Figure 7(c) indicates that dead angle of

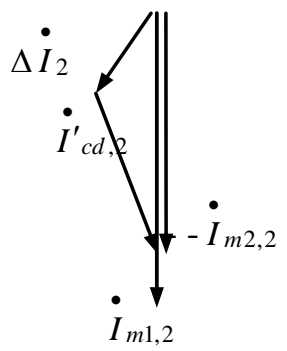

Figure 5. Phasors of second harmonic component under sympathetic inrush between transformers in series.

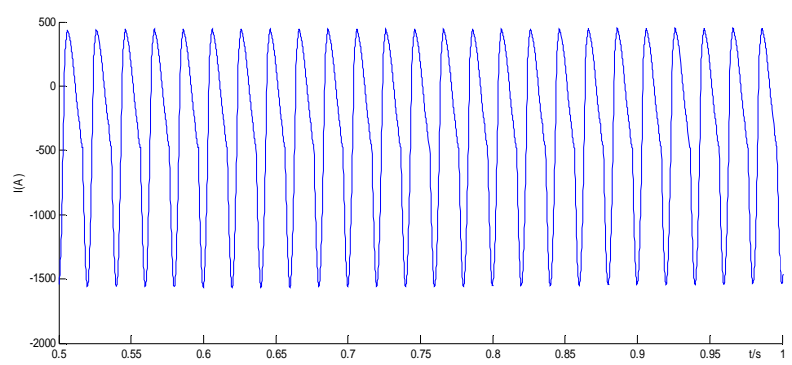

(a) Waveform of Phase A primary winding current of $\mathrm{CT}_{1}$

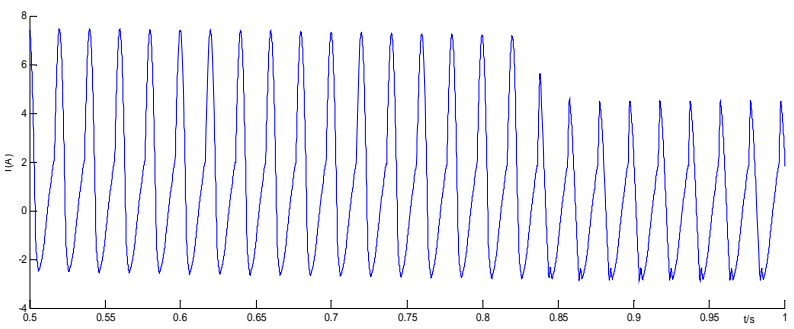

(b) Waveform of Phase A secondary winding current of $\mathrm{CT}_{1}$

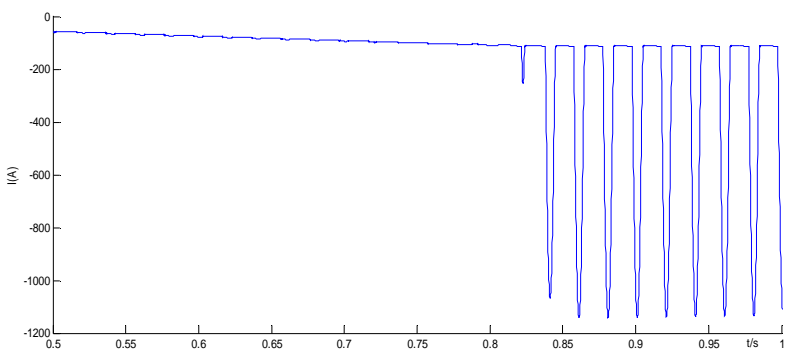

(c) Waveform of Phase A magnetizing inrush of $\mathrm{CT}_{1}$

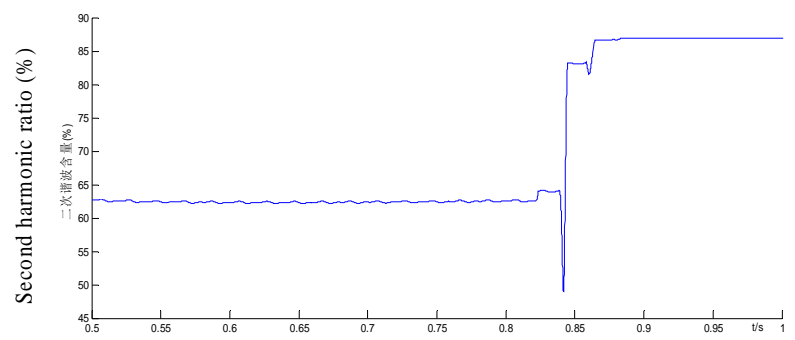

(d) Waveform of Phase Asecond harmonicapp: ds: proportionratio

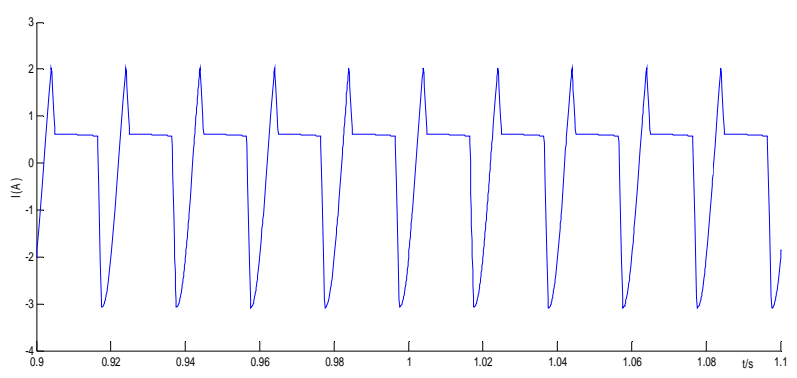

(e) partial waveform of Phase A differential current

Figure 6. Simulation waveforms of differential current under sympathetic inrush between transformers in parallel.

differential current become very small, so dead angle restraint method will be invalid too. 


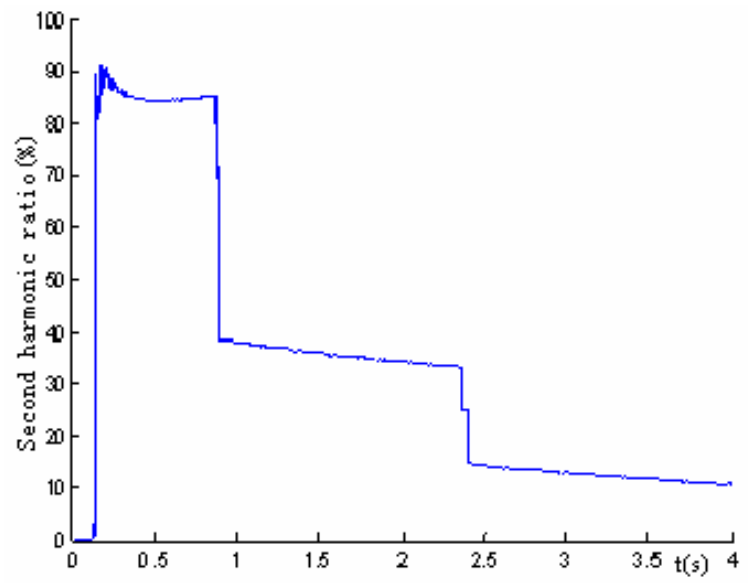

(a) Changing of second harmonic ratio

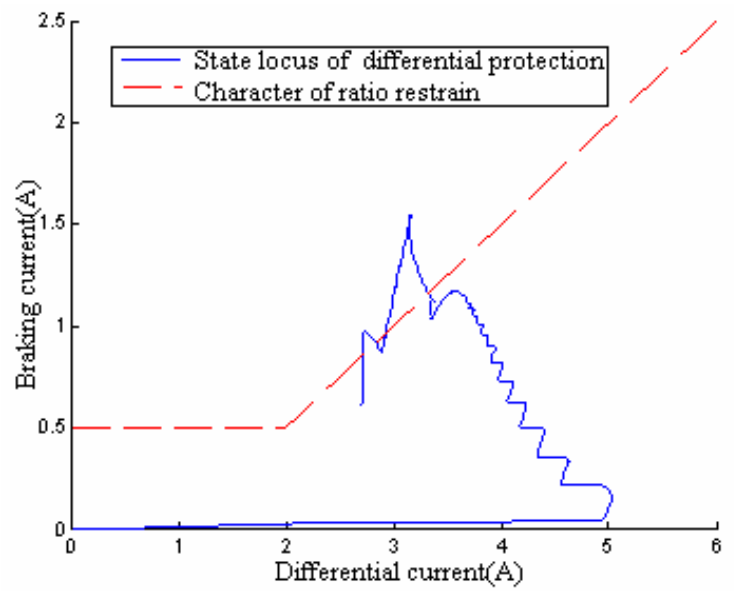

(b) Motion locus of differential protection

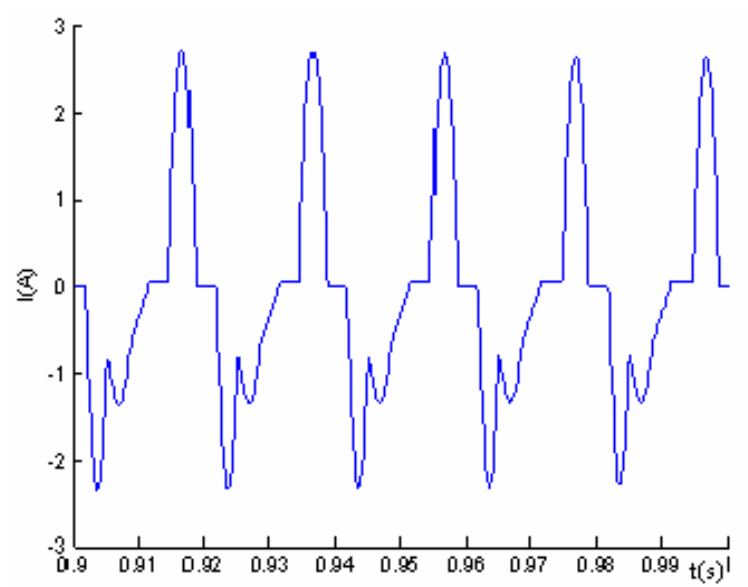

(c) Partial waveform of differential current

Figure 7. Waveforms of mal-operation of differential protection cased by under sympathetic in rush between transformers in series.

\section{Conclusions}

Through theoretical calculating the gain of each har- monic transforming from primary winding to secondary winding of transient saturation CT, it is can be proved that the ability of saturation CT transforming higher harmonics is stronger than that of transforming lower harmonics. Therefore, second harmonic ratio will be amplified by saturated CT. In other word, CT transient saturation itself is not essential reason for differential relay mal-operation.

Theoretical analysis and simulation results show that parallel sympathetic inrush and series sympathetic inrush will lead to different location CT saturated. Parallel sympathetic inrush will lead to CT located system side saturated. Due to second harmonic ratio of differential current increase and dead angle is large, which is help to second harmonic restraint method and dead angle restraint method, so differential protection will not maloperate under parallel sympathetic inrush.

Series sympathetic inrush will lead to CT located load side saturated. While CT saturation leads to the fundamental component of differential current increased where as the second harmonic component of differential current decreased. As a result, the second harmonicratio of differential current will decrease. Moreover, the dead angle of differential current is small. Thus series sympathetic inrush is easy to lead differential relay mal-operation.

\section{Acknowledgements}

Project Supported by National Natural Science Foundation of China (51007035, U1202233, 51267009); Yunnan Natural Science Foundation (2009ZC016M); Kunming University of Science and Technology Talent Training Foundation (KKZ320201004003).

\section{REFERENCES}

[1] G. B. Kumbhar and S. V. Kulkarni, "Analysis of Sympathetic Inrush Phenomena in Transformers Using Coupled Field-circuit Approach,” Proceedings 2007 IEEE Power Engineering Society General Meeting, PES, Tampa,24-28 June 2007, pp. 427-432.

[2] J. Pontt, J. Rodriguez, J. S. Martin, and R. Aguilera, "Mitigation of Sympathetic Interaction between Power Transformers Fed by Long over Head Lines Caused by Inrush Transient Currents," Industry Applications Conference,2007, 42nd IAS Annual Meeting, Conference Record of the 2007 IEEE, New Orleans, 23-27 September 2007, pp. 1360-1363, 2007.

[3] A. MohdZin, Hana AbdullHalimand, S. P. Abdul Karim. "Sympathetic Inrush Current Phenomenon Analysis and Solution for a Power Transformer,'International Review on Modelling and Simulations (IREMOS), April 2011, pp. 601-607.

[4] H. S. Bronzeado, P. B. Brogan and R. Yacamini, "Harmonic Analysis of Transient Currents during Sympathetic Interaction,” IEEE Transactions on Power Systems, Vol. 11, No. 4, 1996, pp. 2051- 2056. 


\section{doi:10.1109/59.544684}

[5] Y. B. Zhou and L. Cao, "Inspection and Analysis of a Maloperation of Transformer Differential Protection and Its Preventive Measures,” Power Systems Technology, Vol.25, No. 20, 2001, pp. 71-74.

[6] G. W. Yu, D. Q. Bi, Z. G. Wang and etc, "Phenomenon of Sympathetic Inrush and Analysis of an Example," Automation of Electric Power Systems, Vol. 29, No. 6, 2005, pp.20-23.

[7] D. J. Li, W. J. Wang and D. Q. Bi, "Analysis of Transient Saturation and Sympathetic Inrush of Transformers," High Voltage Apparatus, Vol. 41, No.1, 2005, pp.12-15.

[8] L. Wei, T. Zheng, G. G. Wang and etc, "Synthetic Analysis on the Causes of Mal-operation and Preventive Measures of Transformer Differential Protection,” Power System Protection and Control, Vol. 36, No. 19, 2008, pp.40-43.

[9] J. H. Wang and J. Q. Li, “The Analysis of a Misoperation of Differential Protection of Transformer," Hydropower and New Energy, Vol. 6, 2011, pp.32-34.

[10] S. F. Huang, J. Gu, T. Zheng and etc, "Mal-operation of Transformer Differential Protection with Inner Bridge Connection and Counter measure," High Voltage Engineering, Vol.37, No.12, 2011, pp.3099-3106.
[11] D. Q. Bi, X. H. Wang, D. J. Li and etc, "Theory Analysis of the Sympathetic Inrush in Operating Transformers," Automation of Electric Power System, Vol. 29, No.6, 2005, pp.1-8.

[12] Y. B. Yuan, D. J. Li and Y. P. Lu, "Physical Mechanism of Sympathetic Inrush of Transformer and Its Influence on Differential Protection,” Automation of Electric Power Systems, Vol.29, No.6, 2005, pp.9-14.

[13] T. Zheng and P. Zhao, "Analysis of Influence Factors of Sympathetic Inrush on Differential Protection and Its Solution," Automation of Electric Power Systems, Vol.33, No. 3, 2009, pp.74-78.

[14] X. S. Zhang and B. T. He, "Influence of Sympathetic Interaction between Transformers on Relay Protection," Proceedings of the CSEE, Vol.26, No.14, 2006, pp. 12-17.

[15] X. F. Sun, H. C. Shu and J. L. Yu, “Comparison of Sympathetic Inrush Influence on Differential Protection between Parallel and Series Transformers," Electric Power Automation Equipment, Vol. 29, No.3, 2009, pp.36-41.

[16] M. L. Jin, X. G. Yin and D. H. You, "Reason of Differential Protection Mal-operation Caused by Complex Sympathetic Inrush and Its Counter measure," Proceedings of the CSEE, Vol. 31, No.1, 2011, pp. 86-72. 